DOI: https://doi.org/10.36910/6775-2524-0560-2020-41-06

УДК 514.181.6+ 514.182

Журило Алла Григорівна, к.т.н., доцент,

https://orcid.org/0000-0003-4084-4622

Національний технічний університет «Харківський політехнічний інститут»

\title{
ПОБУДОВА ТОЧНОЇ ПЕРСПЕКТИВИ КОЛА, ЩО НАЛЕЖИТЬ ПРЕДМЕТНІЙ ПЛОЩИНІ
}

\begin{abstract}
Журило А. Г. Побудова точної перспективи кола, що належить предметній площині. У статті розглянуто основні положення щодо побудови перспективних зображень кіл, які належать предметній площині. Пояснюються складності таких побудов, пропонуються методи спрощення побудов, визначаються необхідні умови для таких побудов. Показано практичне застосування перспективних зображень, встановлена неможливість зображення кіл малих діаметрів в перспективних зображення. Тим самим, пояснюються причини можливої заміни еліпсів при виконанні перспективних зображень овалами без втрати наочності. Наведено приклади перспективних зображень кіл при виконанні креслеників.
\end{abstract}

Ключові слова: перспективні зображення, коло, еліпс, овал, практичне застосування.

Журило А. Г. Построение точной перспективы окружности, принадлежащей предметной плоскости. В статье рассмотрены основные положения по построению перспективных изображений окружностей, принадлежащих предметной плоскости. Объясняются сложности такого построения, предлагаются пути упрощения построений, определяются необходимые условия для таких построений. Показано практическое применение перспективных изображений, установлена невозможность изображения окружностей малых диаметров в перспективных изображения. Тем самым, объясняются причины возможной замены эллипсов при выполнении перспективных изображений овалами без потери наглядности.Приведены примеры перспективных изображений окружностей при выполнении чертежей.

Ключевые слова: перспективные изображения, окружность, эллипс, овал, практическое применение.

Zhurilo A. G. Building the perspective of a circle that belongs to the subject plane. The article discusses the main provisions for the construction of perspective images of circles belonging to the subject plane. The complexity of such a construction is explained, ways to simplify the construction are suggested, and the necessary conditions for such constructions are determined. The practical application of perspective images is shown. it is established that it impossible to image circles of small diameters in perspective images. This explains why ellipses can be replaced with ovals when performing perspective images without losing visibility. Examples of perspective images of circles when performing drawings are given.

Key words: perspective images, circle, ellipse, oval, practical use.

Постановка проблеми. Незважаючи на широкий розвиток комп'ютерної техніки та широке застосування іiі для виконання креслеників, появі вже декількох поколінь програм КОМПАС, AUTOCAD та їхніх аналогів, перспективні проекції широко використовуються у машинобудуванні та архітектурі. Для їх опанування потрібно добре знати їхні властивості та правила їхньої побудови, раціонального розташування, 3 метою отримання найбільш вигідного зображення, та зменшення кількості різних побудов, тощо. На жаль, перспективні проекції мають відповідні лише їм специфічні властивості, які ускладнюють побудову креслеників та їхніх частин, та, відповідно, використання вказаних проекцій на практиці.

Аналіз останніх досліджень і публікацій. Питання щодо точних графічних побудов має велику історичну давнину, беручи свій початок ще в роботах Архімеда, Евкліда та інших вчених. 3 вичерпною повнотою і строгою науковою обгрунтованістю теорія точних метричних побудов була розроблена математиком Гаспаром Монжем, який у 1795 - 1799 рр. опублікував результати своєї двадцятирічної роботи під назвою «Нарисна геометрія» [1].

Серед імен, з якими пов'язаний розвиток наукової праці в області перспективних проекцій, можна згадати видатних вітчизняних вчених: Н. М. Бескіна, О. О. Вольберга, Н. О. Глаголєва, Є. А. Глазунова, А. І. Добрякова, Д. І. Каргина, І. І. Котова, М. О. Риніна, С. О. Смирнова, М. Ф. Четверухіна, С. О. Соловйова [2-6].

У даний час теорія перспективи розроблена докладно і висвітлена в численних працях 3 нарисної геометрії. Питання ж практики побудови перспективних зображень висвітлені в літературі недостатньо. У практиці побудови перспективних зображень часто виникають значні труднощі, обумовлені не тільки недостатньою підготовкою виконавця, але і складністю окремих задач, що вимагають спеціального роз'яснення [6-8].

Положення ускладнюється ще й тому, що за останні $20 . .30$ років практично не публікувалося дослідних робіт із практики побудови перспективних зображень та їі основних законів. Ті ж роботи, що були опубліковані раніше, у більшості випадків розглядають найбільш відомі методи 
перспективних зображень, та розглядають найбільш нескладні задачі.

Невирішені частини проблеми. Метою статті $\epsilon$ визначення причин широкого розповсюдження перспективних зображень, обгрунтування основних властивостей при побудові тіл обертання.

\section{Мета дослідження.}

Продовжуючи дослідження, що розпочато в роботі [11], можна визначити, що перспективні зображення $\epsilon$ найважливішим розділом побудови об'ємних зображень. Перспектива підпорядковується законам i правилам, за якими можна зображати предмети так, як вони представляються нашому оку в просторі. Відомі побудови перспективних зображень методом архітекторів, перспективної сітки, лінійна, панорамна перспектива та інші ії види. Спосіб архітекторів можна вважати різновидом способу сліду променя, коли перспективу не поєднують 3 фронтальною проекцією, а переносять на вільне поле кресленика, або на інший аркуш, при цьому масштабуючи зображення. Як випливає з назви, спосіб широко застосовується для зображення призм, кубів, паралелепіпедів, як складових будівель і споруд. На практиці широко застосовують методи архітекторів з однією точкою сходу, з двома, з опущеним (піднятим) планом і з бічною стіною. При побудові окремої будівлі площину картини зазвичай проводять під кутом $30 \ldots 35^{\circ}$ до фасаду. Для полегшення побудови бажано провести картину через будь-який кут споруди. Згідно вищевикладеним вимогам, можна вказати на наступне побудова перспективи кола даного радіуса, яка, перебуваючи на предметній площині, має центром точку, певною іiі перспективою 0 (Рис . 1), коли лінія t-t' служить підставою картини, лінія $\mathrm{hh}$-лінією горизонту, точка 0 - центральною точкою, а величина відстані точки зору до картини виражена відрізком 1P.

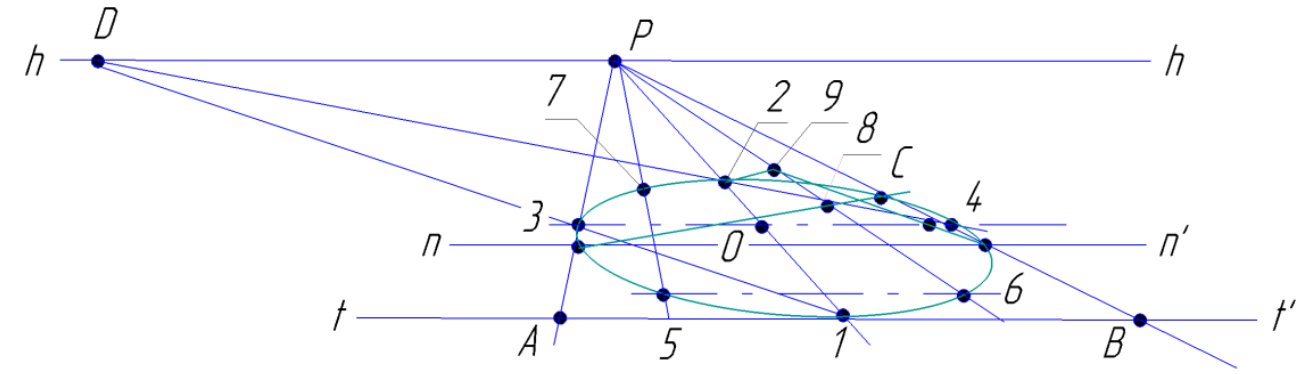

Рис. 1. Побудова перспективи кола

Провівши через точки 0 і $P$ пряму 1Р, отримаємо перспективу прямої лінії перпендикулярної до картинної площини і проходить через центр заданої зазначеними умовами кола; провівши ж через точку 0 лінію 34, паралельну лінії t-t', отримаємо перспективу прямої лінії паралельної картинної площини і яка проходить через центр тієї ж окружності.

Відклавши від точки 1 в обидві сторони по лінії t-t' відрізки $1 A$ і $1 B$, рівні даному радіусу кола, і провівши лінії $A P$ і $B P$, визначимо точки $A$ і $B$ їх перетинів 3 лінією $\mathbf{A B}$; відрізок 34 буде перспективою діаметра, паралельного картинної площині заданої окружності.

Для побудови перспективи діаметра, перпендикулярного до побудованого в перспективі, виконаємо допоміжну побудову, змінивши кут зору на задану окружність, тобто, зробивши ії проектуючою. Якщо в цьому колі (Рис . 2) на двох взаємно перпендикулярних діаметрах 12 і 34 провести допоміжні лінії, що проходять через кінці цих діаметрів, наприклад, 13, 23, 24, то ці лінії складають 3 діаметрами кути в $45^{\circ}$. Звідси (Рис. 1) слід, що якщо через точки $B$ і $C$ (точка відстані) проведемо пряму $4 D$, то ця лінія буде перспективою тієї лінії, яка з лінією t-t' становить кут в $45^{\circ}$, a точка 2 iї перетину 3 лінією $1 P$ визначить кінець діаметра заданого кола, перпендикулярного до діаметру вираженому перспективою $A B$. Якби відрізок $P D$ виражав $1 / \mathrm{m}$ - частину відстані точки зору до картини, то для подальшої побудови необхідно від точки $C$ взяти частину відрізку $04 \mathrm{i}$ крайню його точку з'єднати 3 точкою $D$ прямою лінією, яка, перетинаючись 3 лінією $P 1$, визначить точку 2 , яку шукають.

Точно так же, провівши через точки 1 і $P$ пряму $1 P$ і визначивши точку 2 iї перетину з лінією $4 D$, отримаємо інший кінець того ж діаметру, отже, цей діаметр виразиться в перспективі відрізком 12 .

Таким чином, зазначені побудови дозволяють визначити чотири точки $1,2,3,4$, що належать еліпсу — перспективі заданої окружності.

Для побудови проміжних точок цього еліпса знову звернемося знову до Рис. 2 і зауважимо, що якщо проведемо лінію 69 паралельно діаметру 12, визначимо точку 8 їі перетину з лінією 24 i 
проведемо лінію $38 C$, то ця пряма перетнеться 3 лінією 49, що проходить через точку 4 і точку 9 перетину ліній 96 і 329 в точці $C$, що належить окружності 3241. Дійсно: у трикутнику 394 лінія 96 перпендикулярна до сторони 34, а лінія 24 перпендикулярна до сторони 39; отже, пряма $3 C$, що проходить через точку 8 їх перетину і вершину 3 кута 934, буде перпендикулярна до сторони 94, а якщо кут $3 C 4-$ прямий, то його вершина $C$ знаходиться на окружності 3241.

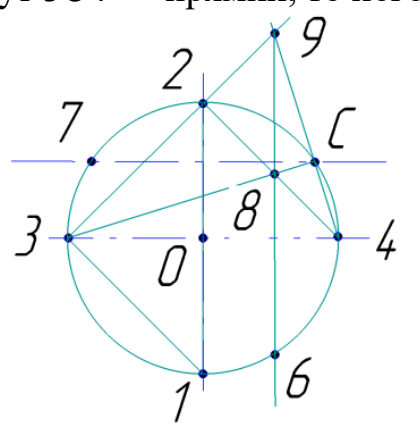

Рис. 2. Допоміжна

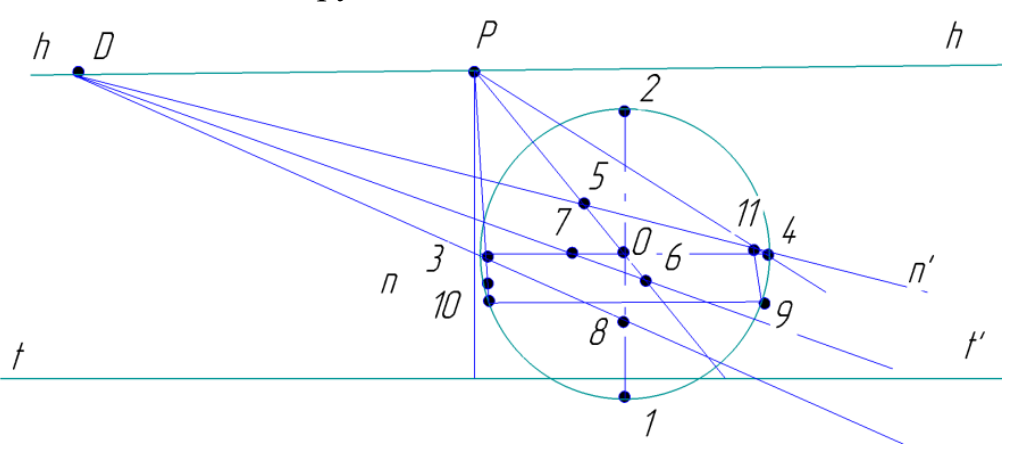

Рис. 3. Побудова перспективи кола побудова

Так як діаметр 12 перпендикулярний до площини картини, то і лінія 69 буде до неї теж перпендикулярна, a, тому iii перспектива буде проходити через центральну точку; перспективи ж інших допоміжних ліній викладеного рішення визначаються перспективами точок, що належать цим прямим, а тому і вказане рішення може бути знайдено на картинній площині.

Отже, через точку $P$ (Рис . 1) проведемо лінію $P K$, а через точки 3 і 9 лінію 39 і визначимо точку М ії перетину з лінією $P 6$, яку і з'єднаємо з точкою в лінією 9. Проведемо лінію $B 9$ і визначимо точку 8 іï перетину з лінією $P 6$, а через точки 3 і 4 проведемо лінію 34 і визначимо точку з ії̈ перетину 3 лінією $B P$, тоді точка $C$ і буде належати еліпсу, службовцю перспективою заданої окружності.

Провівши через точку $P$ іншу лінію і роблячи аналогічно, визначимо точку, що належить тому ж еліпсу, і т.д. ці лінії, що проходять через точку $P$, можна проводити так, що визначається точка еліпса вийде в бажаному приблизно місці слідів, точки еліпса можуть бути визначені на такій відстані одна від одної, що обрис еліпса зробиться досить точним. Застосування комп'ютера істотно полегшить процедуру побудови. Легко помітити, що всі хорди заданої окружності, паралельним картинної площині, в перспективі будуть хордами еліпса 3241 паралельними лінії $\mathrm{t}-\mathrm{t}^{\prime} \mathrm{i}$ діляться хордою 12 навпіл; отже хорда 12 є діаметр цього еліпса, пов'язаний зазначеним паралельним хордам. А тому, якщо відрізок 12 розділимо в точці 0 навпіл, то отримаємо центр цього еліпса, отже положення діаметра, Сполученого діаметру 12, визначиться, провівши через точку 0 лінію, паралельну хорді 34 або лінії t- t'.

Для визначення ж величини цього сполученого діаметра, визначимо ту хорду заданої окружності, яка своєю перспективою дає цей діаметр, а по ній визначимо іï перспективу, тобто діаметр, шо відшукується.

Таким чином, зазначеними побудовами можна визначити перспективи 34 і 12 (Рис. 3) двох перпендикулярних діаметрів заданого кола, 3 яких перший паралельний картинній площині. Розділивши відрізок 12 в точці 0 навпіл, отримуємо центр еліпса, службовця перспективою заданої окружності, а лінія 9-10, проведена через цю точку паралельно лінії t- t', визначить положення діаметра цього еліпса, сполученого $з$ діаметром 12.

Якщо площина заданого кола наведемо положення паралельне картинній площині, повернувши іiі біля лінії діаметра, паралельної лінії t-t', то тоді перспективою заданої окружності буде окружність 3421, описана на відрізок 34, як на діаметрі, а діаметр заданої колу виражався перспективою 12, так само виразиться перспективою 34, тобто діаметр кола 1324 перпендикулярним до ії діаметру 34.

Точка $8 \in$ перспективою деякої точки, що належить діаметру і виражається перспективою $E F$ при первісному положенні площині заданої окружності, а коли ця площина приймає положення паралельне картинної площині, то тоді ця точка виразиться перспективою (точкою), яка знаходиться на діаметрі $E F$ кола 3421. Для визначення цієї перспективи наведемо через точку 8 і точку відстані $D$ лінію $P D$ і визначимо точку 7 iї перетину з лінією 34 . Відрізок 07 визначить в перспективі величину відрізка, вираженого перспективою 06, подібно до того, як відрізок 30 виражає в перспективі величину відрізка, вираженого перспективою 10. А тому, відклавши відрізок 08, що дорівнює відрізку 07, проведемо через точку 8 хорду 9-10 кола 3421, паралельну діаметру 34 . Ця хорда буде 
перспективою хорди, яка відшукується, але тільки при положенні площини заданої окружності паралельної картинної площини. Залишається цю ж хорду визначити перспективою при первісному положенні площини заданої окружності.

Для цього через точки 9 і 10 проведемо лінію 9-10 паралельні лінії Е8 і визначимо, точки перетинів 3 лінією 34, які і з'єднаємо з точкою Р прямими Р10 і P4. Лінії Р10 і Р4, перетинаючись 3 лінією 9-10, проведеної через точку 8 , паралельно лінії 34, визначать відрізок 9-10, який і буде відшукуваним, та пов'язаним $з$ діаметром 12 еліпса 304; а маючи дані по положенню і за величиною двох сполучених діаметрів еліпса, можна визначити ряд точок, що йому належать.

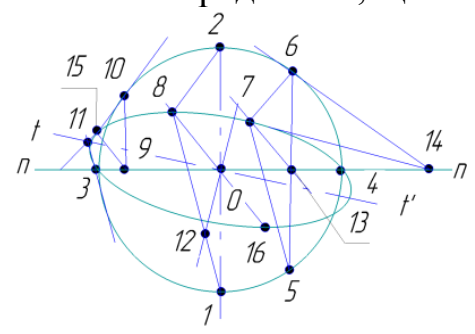

Рис. 4. Допоміжна побудова

Для визначення ж ряду точок, що належать еліпсу, коли дані два його пов'язані діаметра 34 i 08 (Рис. 4.), треба, як відомо, на відрізку 34, приймаючи його за діаметр, описати коло, через центр 0 провести діаметр 12 перпендикулярний до цього діаметру, а точки 2 і 8 з'єднати відрізком 28. На діаметрі 34 взяти якусь точку 13, через неї пронести лінію 7-13, паралельну 08 і 11-9, визначити точку 6 перетину лінії 65 з описаною окружністю і через точку 6 провести лінію 67 паралельну 28, яка перетинаючись в точці 7 з лінією 874, визначити точку, що належить необхідного еліпсу.

Якщо точки 1 і 8 з'єднаємо відрізком 18, а точки 7 і 6 відрізком 76, то ці відрізки будуть паралельні між собою. 3 подібних трикутників 082 і 76-13 отримуємо: 08: 02 = 7-13: 6-13

Але $01=02$ і 6-13 = 5-13, отже: $08: 01=13-7: 13-6$.

Крім того, кут 801 дорівнює куту 7-13-5, отже трикутник 802 подібний трикутнику 76-13, а тому сторона 28 паралельна стороні 76.

На цій підставі можна визначити точку, що належить еліпсу, наступною побудовою.

Описавши на діаметрі 34 окружність 3142 і провівши діаметр 12, до нього перпендикулярний, як і в попередньому рішенні, треба точку 8 з'єднати з точкою 2 лінією 82 . Потім на лінії 34 взяти довільну точку 13 і через неї провести лінію 13-7, паралельну 08 та лінію 13-6, паралельну лінії 12, через точку 5 перетину лінії 13-5 з описаною окружністю провести лінію 57, паралельну лінії 82 і визначити точку 7 iї перетину з лінією 13-7, яка і буде належати вказаному еліпсу.

Коли у еліпса визначено по положенню і за величиною два його сполучених діаметра, то можна визначити по положенню і за величиною його вісі, грунтуючись на наступному.

По-перше, дотична лінія 76, проведена до еліпса в точці 7 і дотична, що проведена у відповідній точці 6 або 7 кола перетинаються між собою в точці 1, що лежить на лінії nn даного сполученого діаметра 34. По-друге, якщо буде описано коло з загальним центром 3 даним еліпсом, який перетинає його в чотирьох точках, то загальні до цих двох кривих лініях чотири дотичні перетинаються між собою попарно на лініях осей цього еліпса, причому ці лінії кути кожної пари дотичних ділять навпіл, як наприклад, лінія tt ділить навпіл кут 10-11-3 двох загальних дотичних 11-3 i 11-10.

Припустимо, що нам дано два сполучених діаметра 34 і 8-16 еліпса, в якому бажаємо визначити напрямок його осей.

На відрізку 34, як на діаметрі, описуємо коло 31423, в ній проводимо діаметр 12, перпендикулярний до діаметру 34, а точку 11 з'єднуємо з точками 1 і 2 лініями 81 і 82. До описаної окружності наведемо дотичну 10-11, паралельну лінії 15-1, і визначимо на еліпсі точку 15 , відповідну точці 10, зазначеною вище побудовою, тобто, через точку 10 проведемо лінію 10-9 і паралельну лінії 12; визначимо точку 9 і іï перетин з лінією 34, а через точку 9 проведемо лінію 9-15, паралельну 0-16 i визначимо точку 15 iï перетину з лінією, проведеної через точку 10, паралельно лінії 81, тобто проведену вже дотичною лінією 10-11. Дотична 3-11 до описаної окружності перетинається з лінією 34 в точці 3, отже, пряма, що з'єднує точки 3 і 15, буде дотична до еліпса в точці 15, звідки бачимо, що лінія 10-11 є загальна дотична до даного еліпсу і до кола 31423.

Провівши до цього кола дотичну 3-11, паралельну лінії 82 і визначивши точку 15, що належить еліпсу за допомогою трикутника, подібного трикутнику 082, побачили б, що лінія 3-11 буде дотичною і до еліпса в точці 3, отже, ця лінія 3-11 буде теж загальна дотична до даного еліпсу і 
описаної окружності. Вище було помічено, що кут 10-11-3, утворений парою загальних дотичних 1011 і 11-3 до еліпса і до зазначеної окружності, лінією осі еліпса ділиться навпіл, то, визначивши точку 11 перетину дотичних 10-15 і 11-3, наведемо через неї і точку 0 прямої 11-0, яка і буде лінією однієї 3 осей даного еліпса; а провівши через точку 0 лінію до неї перпендикулярну, отримаємо положення лінії іншої його осі. Для скорочення ж побудов можна поступити наступним чином: кут 182, дорівнює куту 10-11-3, отже розділивши перший кут навпіл, визначимо напрямок однієї з осей даного еліпса, а провівши через точку 0 лінію 11-0, йй паралельну, визначимо і положення однієї 3 осей еліпса, положення другої осі визначиться, аналогічно.

$\mathrm{Bce}$, що було сказано про побудову перспективи кола, що належить предметній площині, цілком може бути застосовано i для кіл, що лежать не тільки на площинах паралельних $\mathrm{i}$ перпендикулярних до предметної площини, а й на площинах похилих, коли у останніх визначені відповідні лінії сходу і визначено в перспективі їх горизонтальні сліди. Тому для спрощення побудов, без втрати наочності, можна при виконання кресленика перспективних зображень замість побудови еліпсу використовувати овал

Висновок. Визначено, яким чином коло зображується у перспективних зображеннях, доведено, що еліпс, яким зображується коло у перспективі, має теж властивості, що і еліпс при побудові аксонометричних проекцій. Доведено, що при побудові еліпсу, хоч у перспективі, хоч у аксонометрії, основною проблемою залишаються питання точної побудови еліпсу, необхідність використання лекал, потреба виконання чималої кількості допоміжних побудов. Тому, при можливості, пропонується при виконання кресленика перспективних зображень замість побудови еліпсу використовувати овал.

Список бібліографічного опису

1. Гордон В. О. Курс начертательной геометрии: учебник / В. О. Гордон, М. А. Семенцов - Огиевский. М.: Наука, 1976. - 432 с.

2. Ланюк А. В. Аксонометрические проекции: учебник / А. В. Ланюк. - М. : Гос. изд - во лит - ры по строительству и архитектуре, 1956. - 176 с.

3. Порсин Ю. Я. Аксонометрические изображения машиностроительных деталей: учебник / Ю. Я. Порсин. М.- Л. : Машгиз, 1973. - 188 с.

4. Соловьев С. А. Перспектива / С. А. Соловьев.- М.: Просвещение, 1981. - 144c.

5. Соловьев С. Д. та інш. Черчение и перспектива / С. А. Соловьев. - М.: Высшая школа, 1982.

6. Журило А. Г. Теоретичні та практичні основи аксонометрії [Текст] / А. Г. Журило. Навч. посібник. Х.: НТУ «ХПІ». - 2010. - $196 \mathrm{c}$.

7. Петерсон В. Е. Перспектива / В. Е. Петерсон. М.:Просвещение, 1970. - 184 с.

8. Ратничин В. М. Перспектива / В. М. Ратничин. Киев, Вища школа, 1982.- 232 с.

9. Журило А. Г. Деякі питання щодо креслення кіл при побудові аксонометричних проекцій / А. Г. Журило, Є. М. Сівак // Комп’ютерно - інтегровані технології: освіта, наука, виробництво. — 2017. - №26. - С. 93-98. Видавництво Луцького національного технічного університету.

10. Журило А. Г. Построение перспективных изображений при отображении картинной плоскости / А. Г. Журило, Е. М. Сівак, И. Ю. Адашевская // Вестник НТУ «ХПИ». № 17, 2014. С. 73-79.

11. Журило А. Г. Побудова перспективи кола, що належить предметній площині / А. Г. Журило, Є. М. Сівак // Комп’ютерно - інтегровані технології: освіта, наука, виробництво. — 2020. - №39. - С. 17-21. Видавництво Луцького національного технічного університету.

\section{References} 1976. $-432 \mathrm{~s}$.

1. Gordon V. O. Kurs nachertatel'noj geometrii: uchebnik / V. O. Gordon, M. A. Semencov - Ogievskij. - M.: Nauka,

2. Lanyuk A. V. Aksonometricheskie proekcii: uchebnik / A. V. Lanyuk. - M. : Gos. izd - vo lit - ry po stroitel'stvu i arhitekture, 1956. - $176 \mathrm{~s}$.

3. Porsin Yu. Ya. Aksonometricheskie izobrazheniya mashinostroitel'nyh detalej: uchebnik / Yu. Ya. Porsin. - M.- L. : Mashgiz, 1973. - $188 \mathrm{~s}$.

4. Solov'ev S. A. Perspektiva / S. A Solov'ev.- M.: Prosveshchenie, 1981. - 144s.

5. Solov'ev S. A. ta insh. Cherchenie i perspektiva / S. A. Solov'ev. - M.: Vysshaya shkola, 1982.

6. Zhurilo A. G. Teoretichni ta praktichni osnovi aksonometriï [Tekst] / A. G. Zhurilo. Navch. posibnik. H.: NTU «HPI». - 2010. - $196 \mathrm{~s}$.

7. Peterson V. E. Perspektiva / V. E. Peterson. M.:Prosveshchenie, 1970. - $184 \mathrm{s.}$

8. Ratnichin V. M. Perspektiva / V. M. Ratnichin. Kiev, Vishcha shkola, 1982.- 232 s.

9. Zhurilo A. G. Deyaki pitannya shchodo kreslennya kil pri pobudovi aksonometrichnih proekcij / A. G. Zhurilo, E. M. Sivak // Komp’yuterno - integrovani tekhnologiï: osvita, nauka, virobnictvo. - 2017. - №26. - S. 93-98. Vidavnictvo Luc'kogo nacional'nogo tekhnichnogo universitetu.

10. Zhurilo A. G. Postroenie perspektivnyh izobrazhenij pri otobrazhenii kartinnoj ploskosti / A. G. Zhurilo, E. M. Sivak, I. Yu. Adashevskaya // Vestnik NTU «HPI». № 17, 2014. S. 73-79.

11. Zhurilo A. G. Pobudova perspektyvy kola, shcho nalezhyt predmetnii ploshchyni / A. G. Zhurilo, E. M. Sivak // Komp'yuterno - integrovani tekhnologiï: osvita, nauka, virobnictvo. - 2020. - №36. - S. 17-21. Vidavnictvo Luc'kogo nacional'nogo tekhnichnogo universitetu. 